\title{
THE INJURY OF THE REPLACED HIP IN MOTOR VEHICLE ACCIDENTS LITERATURE REVIEW
}

\author{
Zoltán Csernátony ${ }^{1}$, Judit Pálinkás ${ }^{2}$, László Kiss ${ }^{1}$, Sándor Manó ${ }^{1}$ \\ ${ }^{1}$ Department of Orthopaedic Surgery, Medical and Health Science Center, University \\ of Debrecen \\ ${ }^{2}$ Department of Physiotherapy, Medical and Health Science Center, University of Debrecen \\ csz@med.unideb.hu
}

\begin{abstract}
In recent years worldwide there has been a considerable increase in the number of middle and older aged patients who undergo total hip replacement, and following surgery they would again like to live an active life, therefore they take part in everyday traffic as either drivers or passengers of motor vehicles. In head-on collisions there is a relatively high rate of thigh bone, hip joint and pelvic fractures or traumatic dislocation of the hip joint the so called dashboard injury, in cases like this a replaced hip is exposed to greater dangers. We searched the literature for biomechanical examinations of these special joint circumstances, since the replaced hip can not be compared to a healthy hip either biologically or mechanically. The reason this is important, because in these patients it might be advisable to find a solution that takes this into consideration during surgery. We could not find literature examining this question on the internet to this day.
\end{abstract}

Keywords: dashboard injury, total hip replacement, head-on collision, dislocation, fracture

\section{Introduction}

The analysis of traffic accidents has numerous variables. An important part of it can be numerated: the number of accidents, geographical location, seasonal, part of the day distribution, number of people involved, financial cost, loss of work days, number of handicaps, the level of handicap, number of deceased, etc. Another part of it can be categorized: mode of involvement, accident circumstance, reason, type of injury, etc. A third part can be modeled: deformity of the vehicles, the function of the active and passive safety systems, and in a paradox manner the dangers of them, also the mechanism of injury to individuals involved.

All this explains why the study of traffic accidents is multidisciplinary. Due to its nature the biggest problem in traffic safety research is the modeling of injuries to people. In these cases there are numerous variables to be considered, that modeling on dummies alone can not completely solve $e^{7,6,2}$. The age, body size, musculature, health status, vigilance, and also the reaction during the accident can greatly affect the injury suffered by the involved individuals. It is a known fact that the driver that realizes the danger early and because of the stress effect tenses the body to prepare for the impact most often obtains less injury than dozed off passenger whose body behaves "lifeless" during the crash. Although this is just a generalization, but from the above mentioned fact we can deduct that to completely validate this, besides the robotized dummy experimentations there is a need for cadaver experiments.

During cadaver experiments we can search for answers to a diverse amount of questions. We can examine the entire body, but it might be more conclusive to perform the biomechanical 
examination on a predetermined part of the body based on mechanism of injury. While the crash dummy examinations performed under standardized conditions will give similar results therefore a low number of cases is sufficient, in cadaver examination because of the above mentioned diversity a higher number of tests are required.

Based on different estimations there are about 500,000 total hip replacement surgeries performed yearly worldwide, but according to the morbidity statistics of the North-American population about five times as many should be performed. It is an important fact that the majority of these operations are performed in developed countries with high social standards which means longer life expectancy, greater demand for active lifestyle after the operation, and in these countries motorization is significant. Therefore after the total hip replacement surgery a high percentage of patients drive or ride in motor vehicles, because of this in clinical practice we more frequently encounter hip prosthesis dislocation or periprosthetic fracture due to traffic accidents.

This problem is also interesting from a biomechanical point of view ${ }^{3}$. The healthy hip joint

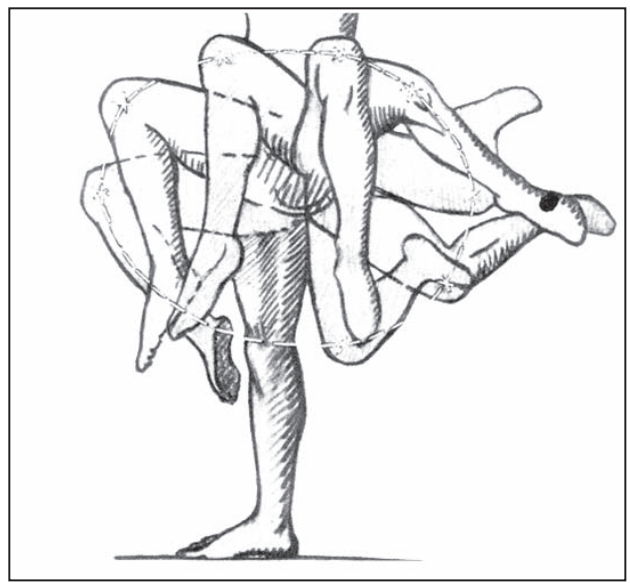

Figure 1. The movements of the hip joint is a spherical joint with three degrees of freedom, which is capable of different degrees of rotation around the three main axes (Figure 1).

In case of joint wear - according to the most wide spread technique - we substitute this spherical joint with a polyethylene cup inserted into the original acetabulum, and we cut the worn femoral head with the neck and insert a stem into the femoral canal, which articulates with the inserted cup through a 22,2, 26, 28 or $32 \mathrm{~mm}$ diameter steal spherical head. This way we copy the natural joint which guarantees that the physiologic movements return after the surgery (Figure 2).

This new joint is made out of lifeless material, and the capsule around the hip no longer exists so the prosthesis reacts to forces in a completely different manner and it also does not have regeneration capabilities, because of these reasons in time it wears and requires exchange. The ten year survival rate is $90 \%{ }^{4}$.

At the same time we noticed that there are disproportionately few lectures at conferences that deal with the mechanics of hip replacement patients suffering traffic accidents involv-

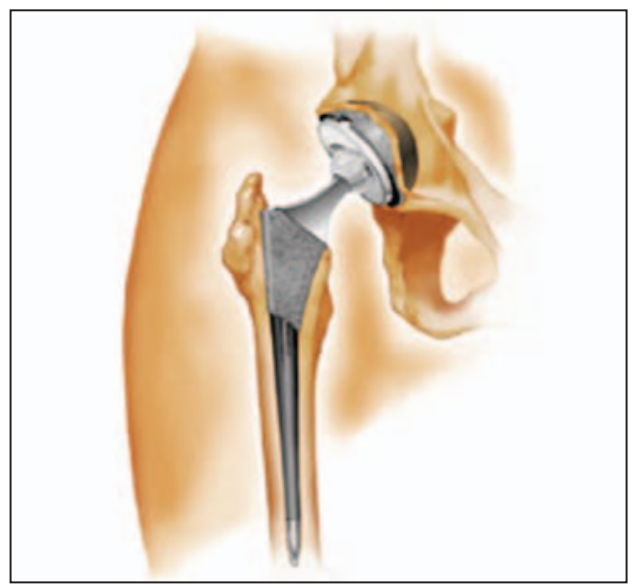

Figure 2. The schematic drawing of a replaced hip 
ing the hip, and we could not find articles in this topic in the literature ${ }^{1,5}$. We found it interesting to search the web for information pertaining to this and compare with the number of results found on professional medical web sites.

\section{Materials and methods}

In our literature review we used information found on Google and ScienceDirect. We used the below mentioned keywords primarily, and then narrowed our results by increasing the keywords. Once we obtained an easy to handle relevant number of results we read through them to see if there are ones that deal with hip injury in patients with hip replacement.
We set the Google search for exact match in both web and image search, while in ScienceDirect we did not narrow our search to any special journal, but searched all the journals available in the site.

In our preliminary search we used the dummy keyword and received 28,868,651 results. Then we narrowed our search by adding additional keywords. These were the following: car crash, biomechanics, dashboard injury, pelvic fracture, dislocation hip arthroplasty. We used these keywords combined in different fashions and obtained the following list.

\section{Results}

Our search results are shown in Tables 1, 2 and 3.

\begin{tabular}{|l|r|}
\hline Keyword(s) & Number of results \\
\hline dummy & $28,800,000$ \\
\hline dummy car crash & 188,000 \\
\hline dummy car crash biomechanics & 8,650 \\
\hline dummy car crash biomechanics dashboard injury & 2,360 \\
\hline dummy car crash biomechanics dashboard injury pelvic fracture & 321 \\
\hline dummy car crash biomechanics dashboard injury pelvic fracture dislocation & 180 \\
\hline dummy car crash biomechanics dashboard injury pelvic fracture dislocation hip arthroplasty & 137 \\
\hline dummy car crash hip arthroplasty & 16,000 \\
\hline car crash hip arthroplasty & $1,580,000$ \\
\hline dummy car crash biomechanics dashboard injury dislocation hip arthroplasty & 229 \\
\hline
\end{tabular}

Table 1. The results of web search found on www.google. hu

\begin{tabular}{|l|r|}
\hline Keyword(s) & Number of results \\
\hline dummy & 2,920 \\
\hline dummy car crash & 22,000 \\
\hline dummy car crash biomechanics & 5,840 \\
\hline dummy car crash biomechanics dashboard injury & 134 \\
\hline dummy car crash biomechanics dashboard injury pelvic fracture & 34 \\
\hline dummy car crash biomechanics dashboard injury pelvic fracture dislocation & 12 \\
\hline dummy car crash biomechanics dashboard injury pelvic fracture dislocation hip arthroplasty & 1 \\
\hline dummy car crash hip arthroplasty & 77,900 \\
\hline car crash hip arthroplasty & $1,310,000$ \\
\hline dummy car crash biomechanics dashboard injury dislocation hip arthroplasty & 4 \\
\hline
\end{tabular}

Table 2. The results of images found on www.google.hu 


\begin{tabular}{|l|r|}
\hline Keyword(s) & Number of results \\
\hline dummy & 65,731 \\
\hline dummy car crash & 924 \\
\hline dummy car crash biomechanics & 302 \\
\hline dummy car crash biomechanics dashboard injury & 18 \\
\hline dummy car crash biomechanics dashboard injury pelvic fracture & 5 \\
\hline dummy car crash biomechanics dashboard injury pelvic fracture dislocation & 1 \\
\hline dummy car crash biomechanics dashboard injury pelvic fracture dislocation hip arthroplasty & 0 \\
\hline dummy car crash hip arthroplasty & 5 \\
\hline car crash hip arthroplasty & 37 \\
\hline dummy car crash biomechanics dashboard injury dislocation hip arthroplasty & 0 \\
\hline
\end{tabular}

Table 3. The results found on www.sciencedirect.com

Understandably we found an extremely large number of hits for the word dummy, because of the wide definition of the word (1. an imitation of a real or original object, intended to be used as a practical substitute, 2. a stupid person, 3. a silent or taciturn person, 4. a person or an agency secretly in the service of another, 5. one of a set of model pages with text and illustrations pasted into place to direct the printer, 6. the partner in bridge who exposes his or her hand to be played by the declarer, 7. a character or other piece of information entered into a computer only to meet prescribed conditions, such as word length, and having no effect on operation). Only a fraction of these results dealt with crash test dummies. On image search we found fewer than 20 different dummies a part of which was the classical built dummy, but more and more appear that are constructed with finite element techniques. Searching for pelvic injuries in dummies and when using pelvic fractures in association with hip replacement resulted in much lower number of hits. Searching under car crash hip arthroplasty on ScienceDirect resulted in 37 hits, but all these articles dealt with the requirement for hip arthroplasty due to the sustained injury and not with the mechanism of injury in patients with hip replacement, and surgical solution in these cases.

\section{Discussion}

The number of patients with hip arthroplasty greatly increases year by year. Furthermore more and more young individuals and older ones that want to live an active life undergo surgery. Since there are a number of surgical techniques used to implant hip prosthesis and even more types of implants available on the market since its modern introduction in 1961, it would be interesting to find out the mechanism of how the different types of surgical techniques and prosthesis types behave during a motor vehicle accident involving the hip area. This information could be used to reconsider the details of some surgical techniques, and also modify - as an option for patients with hip replacement - the active and passive safety systems in motor vehicles. Crash test dummies alone can only determine the size and direction of forces acting on the hip joint in different types of motor vehicle accidents, based on the information from these test, cadaver examinations are necessary to analyze the extent of injury in normal joint circumstances and in the replaced joint. 


\section{REFERENCES}

1. Batman $M$, Seliktar $R$. Characterization of human joint impedance during impulsive motion. J Electromyogr Kines 1993;3(4):221-30.

2. Crash test dummy Facts, Discussion Forum, and Encyclopedia. Available from:

http://www.absoluteastronomy.com/topics/

Crash test_dummy

3. Csernátony Z, Vereb Gy. Biomechanik der Bewegungsorgane. In: Damjanovich S, Fidy J, Szöllősi J, editors. Biophysik für Mediziner. Budapest: Medicina; 2008;351-68.
4. Lakatos J, Szendrói M. Felnôttkori csípőízületi betegségek. In: Szendrôi M, editor. Ortopédia. Budapest: Semmelweis; 2005;341-54.

5. Miltner E, Salwender HJ. Injury severity of restrained front seat occupants in car-to-car side impacts. Accident Anal Prev 1995;27(1):105-10.

6. Mullins J. The human crash test dummy. New Sci 2007 May 05;194(2602):50-1

7. Vincze-Pap S. Az emberi túróképesség határai, avagy hogyan fejlődött és milyen egy korszerú ütközốbábu? Available from: http://www.autokut.hu/ au_vps_babu.htm

The project established by the support of the National Office for Research and Technology.

\section{Dr. Zoltán Csernátony}

Department of Orthopaedic Surgery, Medical and Health Science Center, University of Debrecen

H-4032 Debrecen, Nagyerdei krt. 98.

Tel.:(+36) 52 255-815 


\section{ORVOSI CÉLÚ ALKALMAZÁSOK 3D PRINTING TECHNOLÓGIÁVAL}

\section{PROTOTÍPUSGYÁRTÁS MŰSZAKI DOKUMENTÁCIÓ ALAPJÁN}

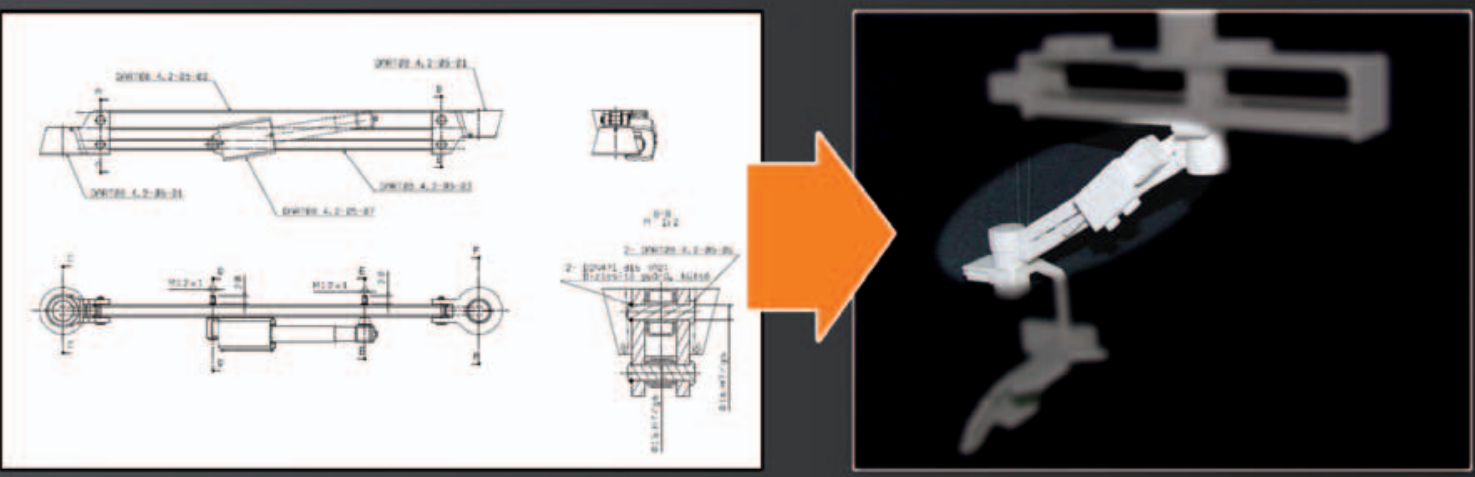

CRANIOPLASTICA MÉRNÖKI TÁMOGATÁSA

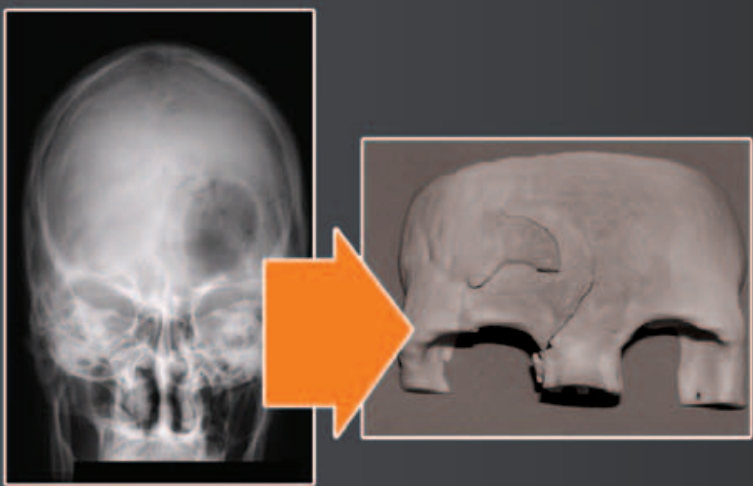

REFERENCIA EGYÜTTMŨKÖDÉSEINK:

- DeBreceni Egrtem, IDEgSebészeti KLINIKA

- SZEgedi Tudományegyetem, Idegsebészeti Klinika

- Plasztika $2000 \mathrm{KFT}$.

- Hydrastat Mérnōki Iroda KFt.

NEHÉZ ESETEK MODELLEZÉSE

- Sanatmetal Kft.

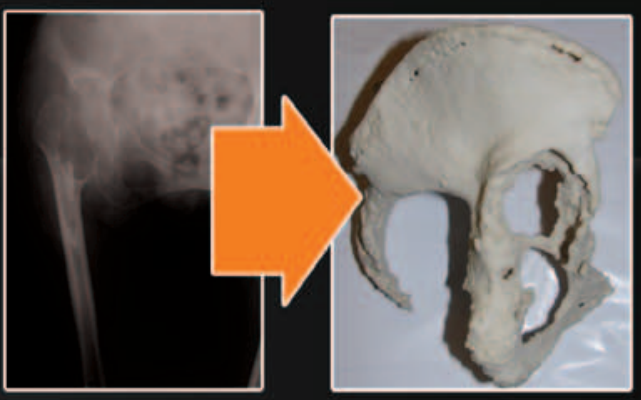

Debreceni Egyetem, OEC Ortopédiai Kuinika, BiombChanikai Laboratórium +3652 415-155/77707

CSZ@MED.UNIDEB.HU

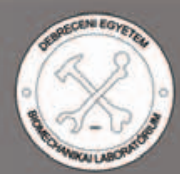

